\title{
The Philosophical Analysis For Engineering Management Education
}

\author{
Weihua Zhu ${ }^{1, \mathrm{a}}$, Qigao $\mathrm{Hu}^{2, \mathrm{~b}}$,Junwei Zheng ${ }^{3, \mathrm{c}}$ \\ ${ }^{1}$ National University of Defense Technology, Changsha, 410072,China \\ ${ }^{2}$ National University of Defense Technology, Changsha, 410072,China \\ ${ }^{3}$ Central South University, Changsha, 410075, China \\ aemail: 45206544@qq.com, bemail:13308492472@189.com \\ cemail: ningzhibo@126.com
}

Keywords: engineering management; education; competence model

\begin{abstract}
The engineering management has the systematic, integrative and complicated nature, which thus presents higher requirements for the engineering manager. The aim of engineering management education includes the imparting of knowledge and the cultivating of intelligence. Knowledge is the tool for human beings to understand and change the nature. Intelligence is always closely with persons, and is shaped by the philosophical spring and the humane spring at the same time, specifically, intelligence cultivation for the engineering manager should start with the establishment of their confidence, responsibility and tolerance.
\end{abstract}

\section{Introduction}

The engineering is the social practice action with the purpose and the organization, during the construction. In order to attain the engineering' objectives, engineering management need to make decision, plan, organize command and control efficiently under the flexible and time-limit organization. So, for the engineering management, the project is the object and the engineering manager is the subject, the relationship between them can be explained again and again with the reforming of the engineering management practice. Because the modern engineering management has exceeded economy and technology category, the engineering management education need to focus on research the new engineering management practice from the higher view, analyze the abilities of the engineering manager. It is important and meaningful that we develop the new field of the human and the philosophy for the engineering management education.

\section{Analyze and research}

A. Analyze the engineering management through the view of the philosophy and the human

1) The engineering management activity_ practice-cognition-new practice: the engineering management activities are dialectical: practice-cognition-new practice-new cognition, the knowledge which can guide the practice spring up and develop along the spiral route. For the engineering management, the engineering is the object and the engineering manager is the subject, the relationship between them is cooperative and harmony mutually. The engineering management can use the system engineering method for reference owing to its systematic characters, such as integrity, hierarchy, open nature and synthesis. Attaching the system engineering method to the project ideology, can embody the applying of the unifying universe ideology in the engineering management knowledge [1].

2)The engineering management organization — - the human subjective initiative :the engineering management is operated by the flexible organization. How to put into effect the human subjective initiative? How to deal with the relationship between the universality and the individuality correctly? These problems contain the rich philosophy connotation. So, we need to focus on the cooperation and the division of the project management organization, pay attention to the new role of the human in the flexible, democratic and net-work organization. 
3)The engineering management value — harmonious management: in the 21 century, when the human engineering activities are more frequent, the project scales are more ambitious, the vigorous development of the projects brings the huge benefit for us, and at the same time it is also along with the catastrophic damage to the earth, such as environmental contamination, resources and energy crisis and so on. It is the time to build the new evaluation criterion for the engineering management. The application of the harmonious management has significant theoretical and practical value [2].

B. Analyze the qualities and construct the quality model of the engineering manager

The engineering managements have the systematic, integrated, complicated nature, which require the engineering manager must have composite qualities. We can summarize them as following three qualities: the quality of team management, the quality of professional management, the quality of self-management.

1) The quality of team management: the team is formed by the group of person who share beliefs and values, have complementary skills, hope to fight for the same purpose. The team management includes the following nature:

a)The diversity of members

b)weaken leadership roles and share power

c)participate together and response collectively

d)communicate deeply, cooperate and trust mutually

The theory about team management believes that the person is expert in the only one major, so the team can solve the problems better for the engineering. The practice also proves that it is true, because the effective team is able to adapt to the volatile market and achieve the goal. Based on the analyzing of the team management characteristics, these are the essential factors for the quality of team management, such as the ability of configuring the diversity of manpower resource, the consciousness of weakening leadership roles, emphasizing the engineering goals as the soul of the working, paying attention to the manpower resource management strategy, focusing on the active learning and creating the learning team.

2) The quality of professional management: academician of China Engineering Academy, Researcher Liu Yuanzhang thinks the engineering managers are special because of their knowledge structure [3]. For the engineering management, its working not only requires the technical assistance, but also has the multi-level participating and the economic constraints. So, while the engineering managers deal with workings, they need to consider the technical, economic, legal, social issues at the same time. Accordingly, the engineering management knowledge covers management, engineering science, economics, law, sociology, behavioral science, mathematics, and statistics and so on. The strong professional management skill is the important ability in the career. The skill has the following characteristics: the ability of achieving the knowledge complementarity, the broad basic knowledge, the superb professional knowledge, the continuous innovation ability etc.

3 )The quality of self-management: the famous management expert-Peter. Drunker point out: in this century, the outstanding manager is more significant than the innovation of technology or network, and the self-management is the basic factor for the predominant manager. The qualities of self-management include the self-confidence, willpower, self-understanding and personal charm etc.

4) "ladder-shaped" competence model for the quality of engineering manager: Competence Model for the engineering manager means integration of characteristic elements which the good engineering manager has, and CM describes the behavior according to the core ability of the different level manager. The quality of self-management, the quality of professional management and the quality of team management are the organic parts in this modal, each factor permeate each other and they have the climactic relation. 


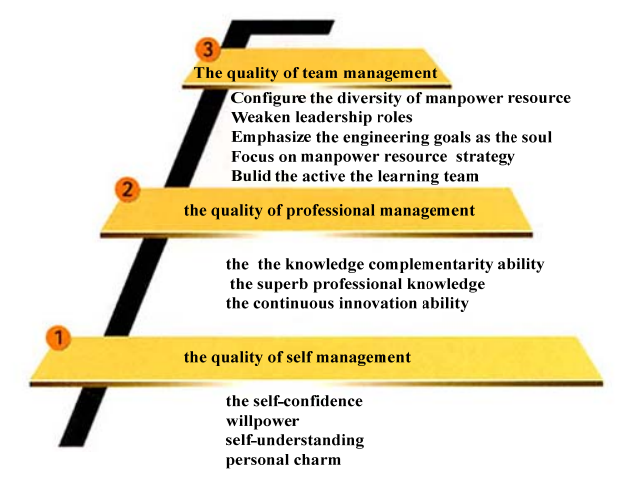

\section{Recommendations}

Figure 1 “ladder-shaped” competence model

A. Cultivate the confidence of the engineering manager

The former American president Herbert Hoover once describe the engineering: "it is the marvelous occupation, the feeling of achievement or pride is strong when the program becomes the reality." For the engineering management education, we should always guide the students to establish the value: the engineering management is very valuable and meaningful. Case teaching, practice teaching or the lectures, reports or forums which are made by the successful engineering managers is the smart choice. The students can enjoy the happiness and success of the occupation and the confidence or the sense of mission can be imbued.

B. Cultivate the conscientiousness of the engineering manager

Yuanpei Cai argues that the education can impel us to seek the meaning of life, deal with the relationship between the human and society, the human and environment better [4]. The educators focus on the perfect personality and personality development. However, the engineering with the complexity, uniqueness and irreversibility is the special activity. So during the period of construction, the concept, ability and attainment of the engineering manager plays a critical role for decision-making and implementation of engineering. How to cultivate the conscientiousness of the engineering manager? The author thinks that now we lack the education about the deep love for your work. The responsibility is derived from the love. The famous entrepreneur Inamori Kazuo once said: "Love leads to success, love ignite passion, Love spur inspiration" [5].

C. Cultivate the tolerance of the engineering manager

The engineering activities involve not only the large amount of technology, but also the social factors, such as the economy, the culture and the environment. The finial values of engineering have something to do with all the aspects of the interests. The intelligence of the human can provide the solution when the managers need to copy with the uncertain environment and complex problems.The tolerance can help each participant better collaborate so that the engineering can realize the value maximization.

\section{Conclusions}

The modern construction demands that the concept, strategy, organization, methods of the engineering management adapts to the characteristics of the new era. Many tremendous changes need fusion technology exquisite and philosophical wisdom. So, as the engineering managers, it is necessary to understand the nature and the pattern of the engineering management through the view of dialectical philosophy. If the management theories are still fixed on one model, the methods probably are sank into the isolation and become rigid. In conclusion, we should add the philosophical and humane factors in order to construct the new scientific development concept, systematic perspective and harmonious view.

\section{References}


[1]Yin runyu. Engineering philosophy [M]. Beijing: Higher Education Press.2007

[2]Liu yuanzhang. My opinion of the management engineering education [J]. Journal of Tianjin University (Social Science Edition),2006,(9):321 324.

[3] P.Aarne Vesilind Alastair S.Gunn. Project, Ethic and Environment. Translator:Wu xiaodong, Wong run. Beijing: Tsinghua University press,2003:83.

[4]Zhang qin, Cai yuanpei's personality education and harmonious development [J]. Education and Occupation,2008,(21):35 37.

[5]Zhong fang, Inamori Kazuo’s company manage philosophy [M]. The Commercial Press.2007. 